\title{
Knowledge and Awareness About Different Layering Techniques of Composites and their Post-Operative Sensitivity Among Dental Students
}

\author{
Thanish Ahamed $\mathrm{S}^{1}$ and Manish Ranjan ${ }^{2}$ \\ ${ }^{1}$ Saveetha Dental College and Hospitals, Saveetha Institute of Medical and Technical Sciences, \\ Saveetha University, Chennai - 600077, India \\ ${ }^{2}$ Reader, Department of Conservative Dentistry and Endodontics, Saveetha Dental College and Hospitals, \\ Saveetha Institute of Medical and Technical Sciences, Saveetha University, Chennai - 600077, India
}

\section{ABSTRACT}

Esthetically pleasing restorations are much desirable in modern day conservative dentistry. Composite resins are currently the most popular tooth coloured restorative material. Despite excellent esthetic results, due to polymerization shrinkage they are prone to marginal leakage and thus sensitivity. To minimize the demerits, efforts are still made in terms of different layering techniques of composites. The aim of the study was to assess the knowledge and awareness about different layering techniques of composites and their post-operative sensitivity among dental students. A questionnaire comprising 10 questions were formulated with 5 questions relating to knowledge, 5 questions regarding awareness about different layering techniques of composites and their post-operative sensitivity. The questionnaire was then administered among 100 dental students including 50 male students and 50 female students. The responses were then subjected to statistical analysis. Frequency distribution and percentage and chi-square test were done to find the association between the response of each question with respect to gender.. The present study showed that even though the majority of students were aware about different layering techniques employed in composite restoration, the knowledge about specific techniques was still inadequate. Also, females had better knowledge and awareness as compared to males.

KEY WORDS: RESTORATION, ESTHETICS, COMPOSITES, SENSITIVITY.

\section{INTRODUCTION}

Patient expectations of esthetics have increased dramatically in the last decade. Introduction of polymerizing resins in the 1950s opened up new avenues for dentists and ever since remains one of the most popular treatments in dentistry. (Bohaty et al., 2013)

\section{ARTICLE INFORMATION}

*Corresponding Author: manish@saveetha.com

Received 24th July 2020 Accepted after revision 28th Sep 2020

Print ISSN: 0974-6455 Online ISSN: 2321-4007 CODEN: BBRCBA

Thomson Reuters ISI Web of Science Clarivate Analytics USA and Crossref Indexed Journal

\section{Clarivate
Analytics}

NAAS Journal Score 2020 (4.31) SJIF: 2020 (7.728)

A Society of Science and Nature Publication,

Bhopal India 2020. All rights reserved.

Online Contents Available at: http//www.bbrc.in/

Doi: http://dx.doi.org/10.21786/bbrc/13.8/181
Composite resins are currently the most popular of all tooth coloured restorative materials, which completely replaced silicate cement and acrylic resin as esthetic restorative material.

Composite restorative materials consist of a continuous polymeric or resin matrix in which a filler is dispersed. With the development of acid etch technique and dentin bonding agents, the marginal seal and bonding of composite to tooth structure has drastically improved, hence adding to the longevity of the restoration. (Cenci, Demarco and de Carvalho, 2005) Composite resins have several advantages. These are restorative materials that can bond well to the conditioned tooth surface. Being tooth colored, they are used to give natural appearance to the restored teeth. Tooth preparation for composite resin is very minimal when compared to amalgam

$$
464
$$


preparations and due to the bonding ; it reinforces the tooth improving its resistance form. (Coelho-De-Souza et al., 2008; Correa et al., 2012)

Despite recent improvements in adhesive dentistry, materials and esthetic demands of the patients have contributed to the frequent use of composite materials, post-operative sensitivity still remains a problem. (Gordan and Mjör, 2002) This complication is related to the polymerization shrinkage of the resin-based adhesive materials resulting in internal stress and gap formation, which are more prone to microleakage and post-operative sensitivity between the tooth and the material. (Opdam et al., 1998) previous studies have cited three most common reasons of postoperative sensitivity: polymerization shrinkage of the resin, microleakage around the margins of the restoration, and build-up of residual stress in the tooth after placement of direct composite restoration. (Deliperi and Bardwell, 2002; Tantbirojn et al., 2004; Kang et al., 2007; Arora et al., 2012)

Restoration placement techniques are universally recognized as a considerable factor in the modification of shrinkage stress. By maneuvering specific restorative techniques, stress resulting from constrained shrinkage may be scaled down. (Chandrasekhar et al., 2017) Administering the composite in layers instead of using a bulk technique is recommended to reduce shrinkage stress. Based on this theory, several layering techniques were developed which includes horizontal, vertical, oblique, stratified, split-increment, dual-shade, polychromatic layering techniques. (Tjan, Bergh and Lidner, 1992) It is widely accepted that incremental filling decreases shrinkage stress as a result of reduced polymerization material volume. Each increment is compensated by the next increment, and the effect of polymerization shrinkage is less damaging since only the volume reduction of the last layer can damage the bonded surface. (Giachetti et al., 2006)

Therefore, apart from selection of treatment and material, it is important to have knowledge about the techniques involved in material application. Literature search reveals studies assessing knowledge and awareness about different layering techniques of composites and their post-operative sensitivity among dental students are still lacking. We have numerous highly cited publications on well designed clinical trials and lab studies (Govindaraju, Neelakantan and Gutmann, 2017; Azeem and Sureshbabu, 2018; Jenarthanan and Subbarao, 2018; Manohar and Sharma, 2018; Nandakumar and Nasim, 2018; Teja, Ramesh and Priya, 2018; Janani and Sandhya, 2019; Khandelwal and Palanivelu, 2019; Malli Sureshbabu et al., 2019; Poorni, Srinivasan and Nivedhitha, 2019; Rajakeerthi and Ms, 2019; Rajendran et al., 2019; Ramarao and Sathyanarayanan, 2019; Siddique and Nivedhitha, 2019; Siddique et al., 2019; Siddique, Nivedhitha and Jacob, 2019). This has provided the right platforms for us to pursue the current study. In lieu with the above, this questionnaire study has been designed to assess the knowledge and awareness about different layering techniques of composites and their post-operative sensitivity among dental students.

Table 1. Questionnaire to assess the knowledge and awareness about different layering techniques of composites and their post-operative sensitivity

\section{QUESTIONS TO ASSESS KNOWLEDGE}

1. Which layering technique utilizes different composite shades to replicate the layers of natural teeth?
a) Polychromatic layering technique
b) Bulk technique
c) Vertical layering technique

2. In which technique, series of wedge-shaped composite increments are placed and cured each increment?
a) Polychromatic layering technique
b) Oblique layering technique
c) Vertical layering technique

3. Do you think layering techniques are mostly used in posteriors?

a) Yes

b) $\mathrm{No}$

4. What is the most common drawback of composite restorations?

a) Sensitivity

b) Pain

c) Dislodgement

5. What do you think as the most common reason for post operative sensitivity followed by composite restoration?
a) Polymerization shrinkage
b) Improper isolation during restoration
c) Due to the nature of material itself

QUESTIONS TO ASSESS AWARENESS

6. Are you aware about different layering techniques of composites?

a) Yes

7. Are you aware of the term C-factor?

c) Yes

d) No

8 Are you aware of the difference between vertical and stratified layering technique of composites?
a) Yes
b) No

9. Are you aware that incremental technique lowers the microleakage?

a) Yes

b) $\mathrm{No}$

10. Are you aware of dual-shade layering technique?

a) Yes

b) No

\section{MATERIAL AND METHODS}

A questionnaire comprising 10 questions were formulated with 5 questions relating to knowledge, 5 questions 
regarding awareness about different layering techniques of composites and their post-operative sensitivity. The study protocol was reviewed and approved by the Institutional Ethical Committee of Saveetha Dental College and Hospitals, Chennai. The questionnaire (Table 1) was administered among 100 dental students (50 males and 50 females) of Saveetha Dental College and Hospitals, Chennai. The responses were then subjected to statistical analysis using SPSS Software, Version 23. Frequency distribution and percentage were calculated for responses of the respondents. Chi-square test was performed to find the association between the response of each question with respect to gender. The level for a statistical significance was set at $p<0.05$. The results were demonstrated in the form of bar graphs.

\section{RESULTS AND DISCUSSION}

The present questionnaire study was conducted among dental students to assess the knowledge and awareness about different layering techniques of composites and their post-operative sensitivity. When knowledge was assessed among 100 study subjects, only 52\% answered that polychromatic layering technique utilizes different composite shades to replicate the layers of natural teeth and 50\% gave correct responses that series of wedge-shaped composite increments are placed and cured each increment in oblique layering technique. $67 \%$ of them thought layering techniques are mostly used in posteriors. 83\% suggested sensitivity as the most common drawback of composite restorations; whereas pain and dislodgement were suggested by $7 \%$ and 10\% respectively. Also, when a question regarding the most common reason for post operative sensitivity followed by composite restoration was asked; 78\% opted polymerization shrinkage, $12 \%$ opted improper isolation and $10 \%$ opted nature of material.

Figure 1: Bar graph depicts association between gender and students response. $\mathrm{X}$-axis represents gender and $\mathrm{Y}$-axis represents the number of students. Chi-square test was done and found to be statistically significant ( $p=0.005$ ). Females had better knowledge that polychromatic layering technique utilizes different composite shades to replicate the layers of natural teeth than males.

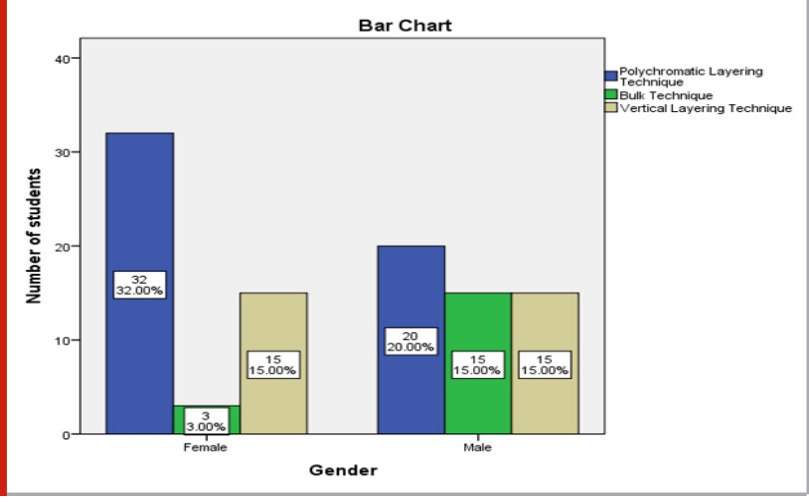

When awareness was assessed, $62 \%$ of them were aware about different layering techniques of composites and 60\% were aware of the term C-factor. 75\% of them were unaware of the difference between vertical and stratified layering technique of composites. Also, 10\% of them were still unaware that incremental technique lowers the microleakage and 82\% were unaware of dualshade layering technique. The association between the response of each question with respect to gender was performed by chi-square test. (Figure 1-10) The success of a composite restoration depends on various clinical conditions like type of composite and bonding system, design of tooth preparation, method of filling the cavity (incremental/ bulk), time and type of finishing and polishing of composite restoration. Parpaiola AR et al suggested that the main cause of restoration replacement was composite shade discoloration (63.8\%) followed by marginal staining (50\%), unsatisfactory restoration anatomy (50\%), marginal fracture (14.9\%), painful symptoms (8.5\%), fractured restoration body (4.3\%), dental fracture (1.1\%) and total displacement of the restoration (1.1\%). (Parpaiola et al., 2009)

Figure 2: Bar graph depicts association between gender and students response. $\mathrm{X}$-axis represents gender and $\mathrm{Y}$-axis represents the number of students. Chi-square test was done and found to be statistically significant $(p=0.000)$. Females had better knowledge that in oblique layering technique series of wedge-shaped composite increments are placed and cured each increment than males.

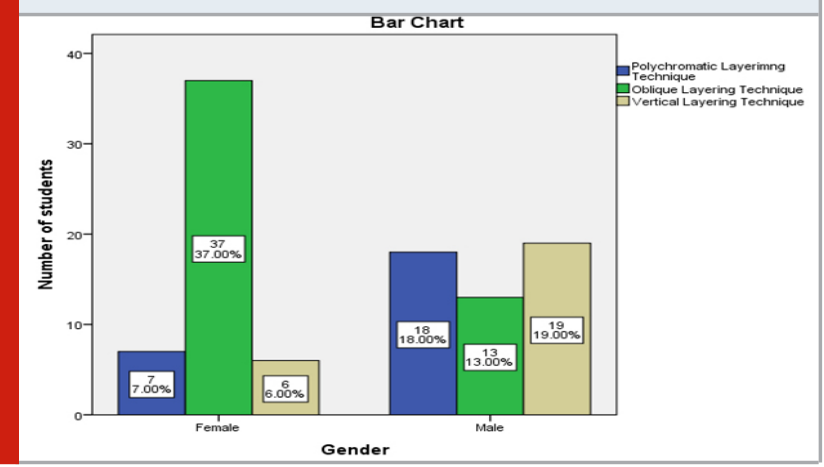

The composite resin contracts by about $1.5 \%$ to $5 \%$ and the mode of polymerization of composite resin is free radical polymerization.(Kwon, Ferracane and Lee, 2012) Significant polymerization shrinkage results in gap formation, secondary caries, marginal leakage and post-operative sensitivity. The layering technique of composite restoration has been recognized as the technique of choice to minimize polymerization shrinkage stresses. (Al-Negrish, 2002; Yamazaki et al., 2006) Literature search reveals numerous studies assessing knowledge towards composite restorations, factors affecting postoperative sensitivity of composite restorations among dental students and practitioners. (Sajad, Shafia and Sharma, 2018)(Pani et al., 2014; Akbar, 2015; Sajad, Shafia and Sharma, 2018) The present questionnaire study was conducted among 100 dental 
students to assess the knowledge and awareness about different layering techniques of composites and their post-operative sensitivity.

Figure 3: Bar graph depicts association between gender and students response. $\mathrm{X}$-axis represents gender and $\mathrm{Y}$-axis represents the number of students. Chi-square test was done and found to be statistically significant $(\mathrm{p}=0.006)$. Females had better knowledge that layering techniques are mostly used in posteriors.

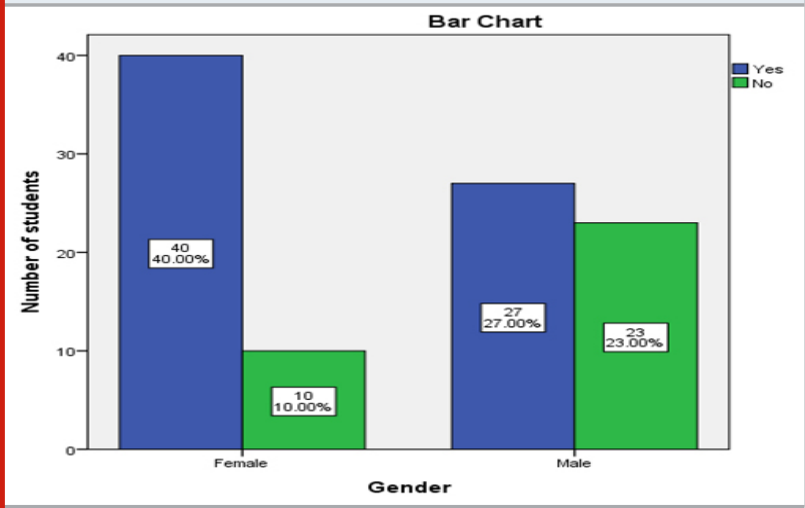

Figure 5: Bar graph depicts association between gender and number of students. $\mathrm{X}$-axis represents gender and $\mathrm{Y}$-axis represents the number of students. Chi-square test was done and found to be statistically not significant $(p=0.339)$. However Females had better knowledge that polymerization shrinkage sensitivity is the most common reason for post operative sensitivity followed by composite restoration

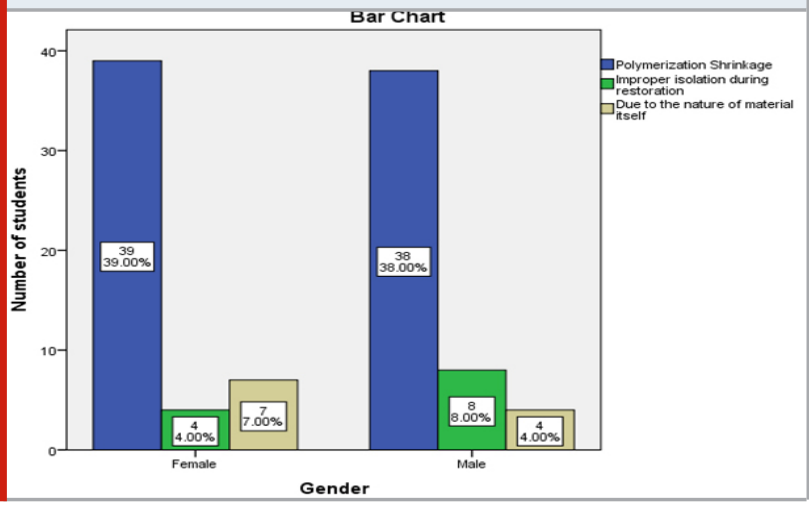

In the present study, 83\% suggested sensitivity as the most common drawback of composite restorations. This is in accordance with previous study among dental practitioners of the United Kingdom, by Gilmour AS et al, reported that $86 \%$ of them suggested postoperative sensitivity as the major issues related to composites. (Gilmour et al., 2009) Also, 78\% opted polymerization shrinkage as the most common reason for post operative sensitivity followed by composite restoration in our study. This is in agreement with a previous questionnaire study by Akbar I et al to assess the knowledge and attitudes of general dental practitioners towards posterior composite restorations in northern Saudi Arabia, where 467
Figure 4: Bar graph depicts association between gender and number of students. $\mathrm{X}$-axis represents gender and $\mathrm{Y}$-axis represents the number of students. Chi-square test was done and found to be statistically not significant $(p=0.176)$. However Females $(45 \%)$ had better knowledge that sensitivity is the most common drawback of composite restorations.

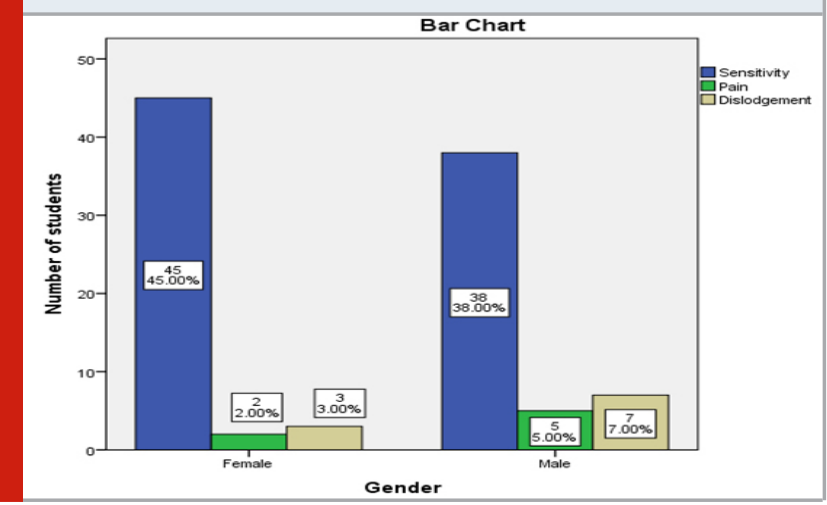

Figure 6: Bar graph depicts association between gender and number of student's awareness about different layering techniques of composites. $\mathrm{X}$-axis represents gender and $\mathrm{Y}$-axis represents the number of students. Chi-square test was done and found to be statistically significant $(p=0.000)$. Females were more aware about different layering techniques of composites than males.

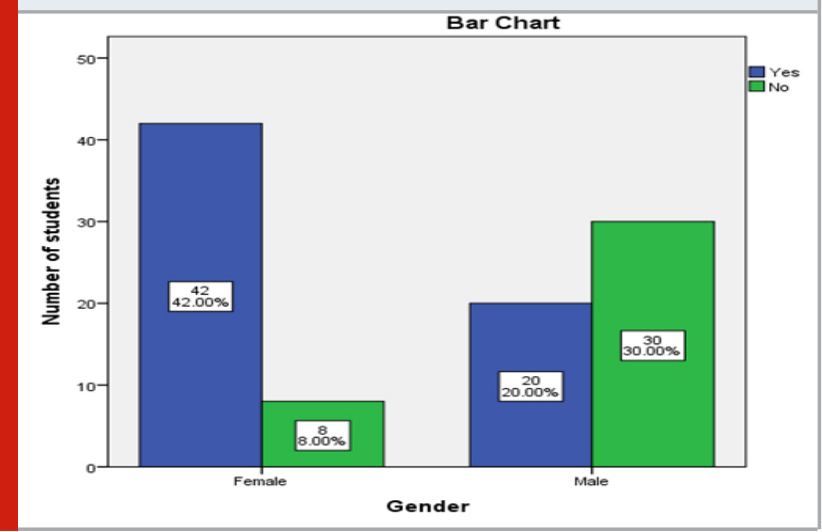

$73 \%$ of them claimed polymerization shrinkage as an inherent problem with composites. (Akbar, 2015) When awareness was assessed in our study, 62\% of them were aware about different layering techniques of composites and 60\% were aware of the term C-factor. These findings are similar to a study among dental students by Pani SC et al. (Pani et al., 2014)

In the present study, 90\% of them were aware that incremental technique lowers the microleakage. Sajad $\mathrm{M}$ in his questionnaire based survey among dental practitioners to assess knowledge and attitude towards composite restorations suggested that 95\% of them preferred incremental technique for placement of composite. (Sajad, Shafia and Sharma, 2018) There are no studies in literature assessing the knowledge about layering techniques in composite restorations. To the 
best of our knowledge, this is the first study to assess the same.

Figure 7: Bar graph depicts association between gender and number of student's aware about the term C-factor. $\mathrm{X}$-axis represents gender and $\mathrm{Y}$-axis represents the number of students. Chi-square test was done and found to be statistically not significant $(p=0.221)$. When compared to males, females were more aware about the term C-factor.

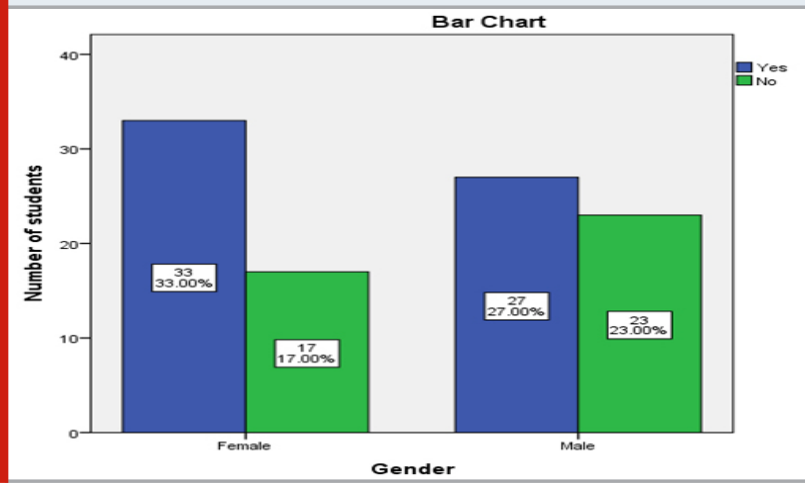

Figure 8: Bar graph depicts association between gender and number of student's aware about the difference between vertical and stratified layering technique of composites. $\mathrm{X}$-axis represents gender and $\mathrm{Y}$-axis represents the number of students. Chi-square test was done and found to be statistically not significant $(\mathrm{p}=\mathbf{0 . 8 1 7})$. When compared to males, females were more aware about the difference between vertical and stratified layering technique of composites.

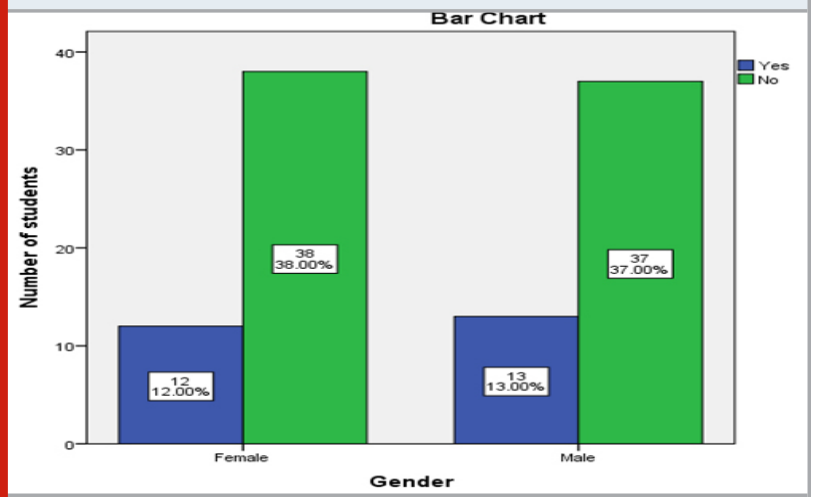

\section{CONCLUSION}

The present study showed that even though the majority of students were aware about different layering techniques employed in composite restoration, the knowledge about specific techniques was still inadequate. Also, females had better knowledge and awareness as compared to males. Therefore, this study highlights that there is a need for continued education about the different layering techniques and its indications to avoid postoperative complications and to achieve better esthetics.
Figure 9: Bar graph depicts association between gender and student's awareness that the incremental technique lowers the microleakage. $\mathrm{X}$-axis represents gender and $\mathrm{Y}$-axis represents the number of students. Chi-square test was done and found to be statistically significant $(p=0.046)$. When compared to males, females were more aware that the incremental technique lowers the microleakage.

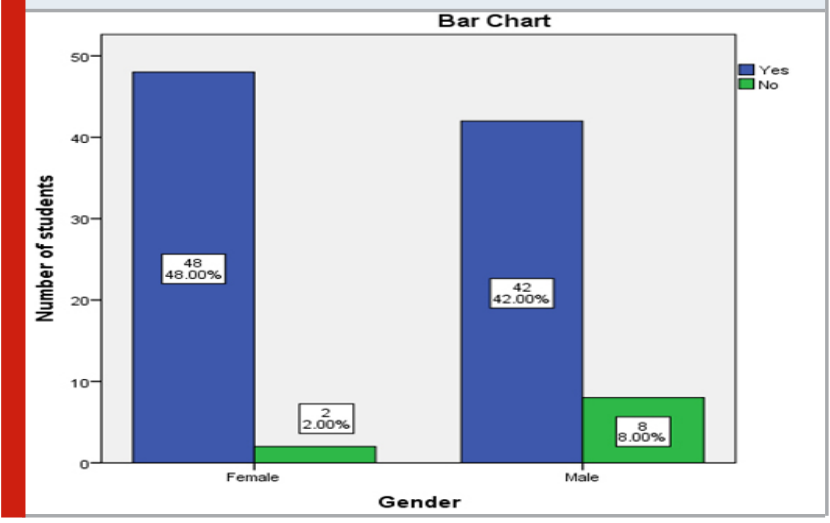

Figure 10: Bar graph depicts association between gender and awareness about dual-shade layering technique. $\mathrm{X}$-axis represents gender and $\mathrm{Y}$-axis represents the number of students. Chi-square test was done and found to be statistically not significant $(\mathrm{p}=\mathbf{0 . 6 0 3})$. When compared to males, females were more aware about dual-shade layering techniques.

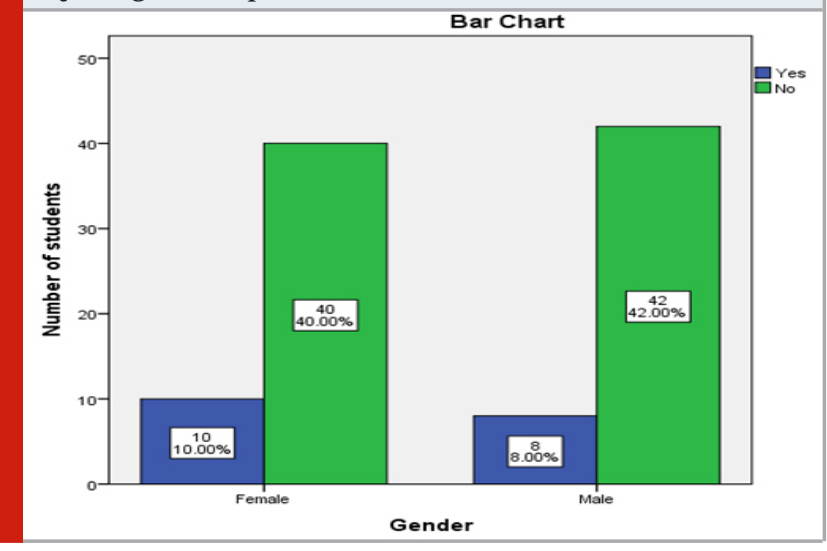

\section{ACKNOWLEDGEMENTS}

The authors of this study would like to express their gratitude towards everyone who facilitated and enabled us to carry out this study successfully.

Conflict of Interest: There were no conflicts of interest as defined by the authors.

\section{REFERENCES}

Akbar, I. (2015) 'Knowledge and attitudes of general dental practitioners towards posterior composite restorations in northern saudi arabia', Journal of clinical and diagnostic research: JCDR, 9(2), pp. ZC61-4.

Al-Negrish, A. R. S. (2002) 'Composite resin restorations: 
a cross-sectional survey of placement and replacement in Jordan', International dental journal. Wiley Online Library, 52(6), pp. 461-468.

Arora, A. et al. (2012) 'A comparative evaluation of dentinal hypersensitivity and microleakage associated with composite restorations in cavities preconditioned with air abrasion - An ex vivo study', Contemporary Clinical Dentistry, p. 306. doi: 10.4103/0976237x.103624.

Azeem, R. A. and Sureshbabu, N. M. (2018) 'Clinical performance of direct versus indirect composite restorations in posterior teeth: A systematic review', Journal of conservative dentistry: JCD, 21(1), pp. 2-9. Bohaty, B. S. et al. (2013) 'Posterior composite restoration update: focus on factors influencing form and function', Clinical, cosmetic and investigational dentistry, 5, pp. 33-42.

Cenci, M., Demarco, F. and de Carvalho, R. (2005) 'Class II composite resin restorations with two polymerization techniques: relationship between microtensile bond strength and marginal leakage', Journal of dentistry, 33(7), pp. 603-610.

Chandrasekhar, V. et al. (2017) 'Incremental techniques in direct composite restoration', Journal of conservative dentistry: JCD, 20(6), pp. 386-391.

Coelho-De-Souza, F. H. et al. (2008) 'Fracture resistance and gap formation of MOD restorations: influence of restorative technique, bevel preparation and water storage', Operative dentistry, 33(1), pp. 37-43.

Correa, M. B. et al. (2012) 'Amalgam or composite resin? Factors influencing the choice of restorative material', Journal of dentistry, 40(9), pp. 703-710.

Deliperi, S. and Bardwell, D. N. (2002) 'An alternative method to reduce polymerization shrinkage in direct posterior composite restorations', Journal of the American Dental Association , 133(10), pp. 13871398.

Giachetti, L. et al. (2006) 'A review of polymerization shrinkage stress: current techniques for posterior direct resin restorations', The journal of contemporary dental practice, 7(4), pp. 79-88.

Gilmour, A. S. M. et al. (2009) 'Placement of posterior composite restorations in United Kingdom dental practices: techniques, problems, and attitudes', International dental journal, 59(3), pp. 148-154.

Gordan, V. V. and Mjör, I. A. (2002) 'Short- and longterm clinical evaluation of post-operative sensitivity of a new resin-based restorative material and self-etching primer', Operative dentistry, 27(6), pp. 543-548.

Govindaraju, L., Neelakantan, P. and Gutmann, J. L. (2017) 'Effect of root canal irrigating solutions on the compressive strength of tricalcium silicate cements', Clinical oral investigations, 21(2), pp. 567-571.
Janani, K. and Sandhya, R. (2019) 'A survey on skills for cone beam computed tomography interpretation among endodontists for endodontic treatment procedure', Indian journal of dental research: official publication of Indian Society for Dental Research, 30(6), pp. 834-838.

Jenarthanan, S. and Subbarao, C. (2018) 'Comparative evaluation of the efficacy of diclofenac sodium administered using different delivery routes in the management of endodontic pain: A randomized controlled clinical trial', Journal of conservative dentistry: JCD, 21(3), pp. 297-301.

Kang Y.-Q. et al. (2007) '[Influence of soft-start irradiation on polymerization shrinkage stress of universal hybrid composite resins]', Zhonghua kou qiang yi xue za zhi = Zhonghua kouqiang yixue zazhi = Chinese journal of stomatology, 42(10), pp. 633-636.

Khandelwal, A. and Palanivelu, A. (2019) 'Correlation Between Dental Caries And Salivary Albumin In Adult Population In Chennai: An In Vivo Study', Brazilian Dental Science, 22(2), pp. 228-233.

Kwon, Y., Ferracane, J. and Lee, I.-B. (2012) 'Effect of layering methods, composite type, and flowable liner on the polymerization shrinkage stress of light cured composites', Dental materials: official publication of the Academy of Dental Materials, 28(7), pp. 801-809.

Malli Sureshbabu, N. et al. (2019) 'Concentrated Growth Factors as an Ingenious Biomaterial in Regeneration of Bony Defects after Periapical Surgery: A Report of Two Cases', Case reports in dentistry, 2019, p. 7046203.

Manohar, M. P. and Sharma, S. (2018) 'A survey of the knowledge, attitude, and awareness about the principal choice of intracanal medicaments among the general dental practitioners and nonendodontic specialists', Indian journal of dental research: official publication of Indian Society for Dental Research, 29(6), pp. 716-720.

Nandakumar, M. and Nasim, I. (2018) 'Comparative evaluation of grape seed and cranberry extracts in preventing enamel erosion: An optical emission spectrometric analysis', Journal of conservative dentistry: JCD, 21(5), pp. 516-520.

Opdam, N. J. et al. (1998) 'Marginal integrity and postoperative sensitivity in Class 2 resin composite restorations in vivo', Journal of dentistry, 26(7), pp. 555-562.

Pani, S. et al. (2014) 'Factors influencing Saudi dental

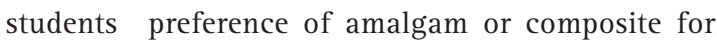
posterior dental restorations', Saudi Journal of Oral Sciences, p. 30. doi: 10.4103/1658-6816.124183.

Parpaiola, A. R. et al. (2009) 'Small cross-sectional survey of composite restoration attributes associated with choices for replacement', Brazilian oral research, 
23(3), pp. 346-351.

Poorni, S., Srinivasan, M. R. and Nivedhitha, M. S. (2019)

'Probiotic strains in caries prevention: A systematic review', Journal of conservative dentistry: JCD, 22(2), pp. 123-128.

Rajakeerthi, R. and Ms, N. (2019) 'Natural Product as the Storage medium for an avulsed tooth - A Systematic Review', Cumhuriyet Dental Journal, 22(2), pp. 249256.

Rajendran, R. et al. (2019) 'Comparative Evaluation of Remineralizing Potential of a Paste Containing Bioactive Glass and a Topical Cream Containing Casein Phosphopeptide-Amorphous Calcium Phosphate: An in Vitro Study', Pesquisa brasileira em odontopediatria e clinica integrada, 19(1), pp. 1-10.

Ramarao, S. and Sathyanarayanan, U. (2019) 'CRA Grid - A preliminary development and calibration of a paper-based objectivization of caries risk assessment in undergraduate dental education', Journal of conservative dentistry: JCD, 22(2), pp. 185-190.

Sajad, M., Shafia, S. and Sharma, N. (2018) 'Knowledge and Attitude of Dental Practitioners Towards Composite Restorations - A Questionnaire based Survey', International Journal of Contemporary Medical Research [IJCMR]. doi: 10.21276/ijcmr.2018.5.8.12. Siddique, R. et al. (2019) 'Qualitative and quantitative analysis of precipitate formation following interaction of chlorhexidine with sodium hypochlorite, neem, and tulsi', Journal of conservative dentistry: JCD, 22(1), pp. 40-47.

Siddique, R. and Nivedhitha, M. S. (2019) 'Effectiveness of rotary and reciprocating systems on microbial reduction: A systematic review', Journal of conservative dentistry: JCD, 22(2), pp. 114-122.

Siddique, R., Nivedhitha, M. S. and Jacob, B. (2019) 'Quantitative analysis for detection of toxic elements in various irrigants, their combination (precipitate), and para-chloroaniline: An inductively coupled plasma mass spectrometry study', Journal of conservative dentistry: JCD, 22(4), pp. 344-350.

Tantbirojn, D. et al. (2004) 'Tooth deformation patterns in molars after composite restoration', Dental materials: official publication of the Academy of Dental Materials, 20(6), pp. 535-542.

Teja, K. V., Ramesh, S. and Priya, V. (2018) 'Regulation of matrix metalloproteinase-3 gene expression in inflammation: A molecular study', Journal of conservative dentistry: JCD, 21(6), pp. 592-596.

Tjan, A. H., Bergh, B. H. and Lidner, C. (1992) 'Effect of various incremental techniques on the marginal adaptation of class II composite resin restorations', The Journal of prosthetic dentistry, 67(1), pp. 62-66.

Yamazaki, P. C. V. et al. (2006) 'Microleakage evaluation of a new low-shrinkage composite restorative material', Operative dentistry, 31(6), pp. 670-676. 